\title{
Numerical modeling of the impact behavior of new particulate-loaded composite materials
}

\author{
A. Arias, R. Zaera, J. López-Puente, C. Navarro * \\ Department of Continuum Mechanics and Structural Analysis, Carlos III University of Madrid, Avda. de la Universidad 30, \\ 28911 Leganés, Madrid, Spain
}

\begin{abstract}
Ballistic efficiency and cost are the main considerations in the design of lightweight armors. Metallic materials have the drawback of their high density. Mixed armors, of ceramic tiles backed by a metallic plate, are an efficient shield against low and medium caliber projectiles since they combine the light weight and high resistance of a ceramic with the ductility of a metal. The drawback is their high cost. The authors developed a new material composed of ceramic particles and a polymeric matrix. It fills the gap between metallic and ceramic materials and could be interesting for applications in which weight is not the primary concern and cost benefits are welcome. A model of the mechanical behavior of this composite is presented in this paper, implemented in a numerical code and validated by experimental results.
\end{abstract}

Keywords: Ballistic efficiency; Ceramic particles; Depth of penetration; Impact; Lightweight armors

\section{Introduction}

The growing interest in problems related to the impact of solids extends beyond the sphere of defense with its coverage of overland vehicles, aircraft, and protection of personnel. In the civil sphere, protection of spacecraft, turbines, civil engineering projects, etc. is essential to avoid damage caused by high velocity impact [1].

The design of protective devices centres around their protective capacity, their low areal density (weight/area), and their cost, the relative importance of these requirements being dependent on the characteristics of the system to be protected. In the case of strongholds or buildings, weight is not a determining factor; here protections of low cost materials can be made more resistant by increasing the wall thickness. But weight becomes a primary consideration in the protection of personnel, vehicles and spacecraft whose mobility must be preserved. In land vehicles, a light protective armor allows the use of a lower-powered engine with no reduction of the speed or maneuverability of the vehicle.

\footnotetext{
${ }^{*}$ Corresponding author. Tel.: +34-91-624-9491; fax: +34-91-6249430.

E-mail address: navarro@ing.uc3m.es (C. Navarro).
}

In aircraft, the weight of each component must be considered, and this includes the density of the armor plating. And of course this is extremely important in the protection of personnel whose mobility is essential.

Various materials can be used to fulfil the requirements of protection. Metals are generally adequate and their cost is reasonable, but their high density is a drawback. The use of ceramic materials is limited by their fragility, as they shatter on account of their poor toughness. So the combination of the light weight and high hardness of the ceramics with the ductility of metallic materials in the so-called mixed protections (Fig. 1) provides ballistic efficiency against the impact of low and medium caliber projectiles [2,3]. The development of structural ceramics $\left(\mathrm{Al}_{2} \mathrm{O}_{3}, \mathrm{SiC}, \mathrm{NiAl}, \mathrm{TiB}_{2}\right.$, etc. $)$ has brought an improvement of the mechanical properties of the armors, but it has meant higher costs, which may be prohibitive in certain applications [4,5]. So the development of a new material that bridges the gap between metallic and ceramic materials may be of interest for low cost applications in which weight is not a design priority.

One of the aims of this work was to develop a composite material that would replace the conventional ceramic tiles and then to evaluate its efficacy against impact. In addition, a model was developed to predict 


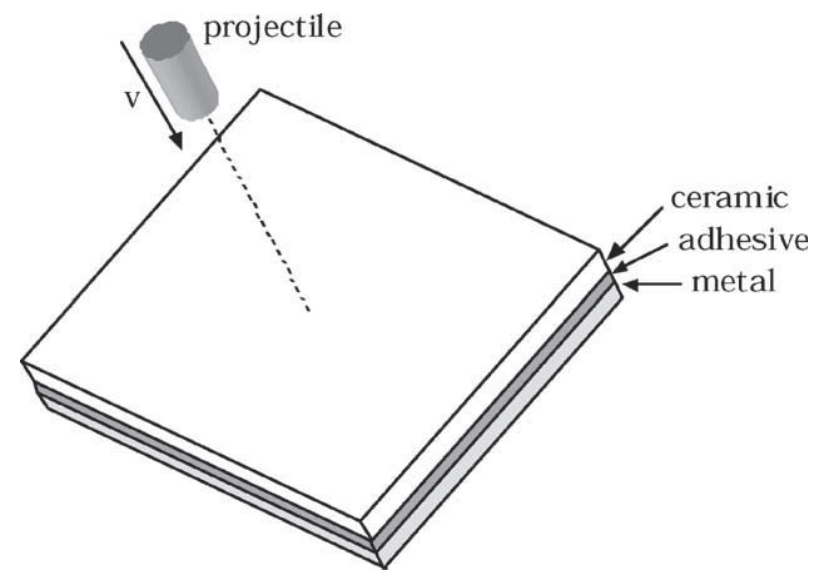

Fig. 1. Sketch of mixed ceramic/metal protection.

the behavior of this material so that its implementation in a numerical code might simplify the design of protections and avoid the high cost of impact tests.

\section{Manufacturing process}

In this work we developed a new composite material made of ceramic particles and resin matrix. Monolithic alumina is the best established ceramic material for lightweight armor and is gaining ground in this field. So we chose $99.4 \%$ purity alumina (ALCOA T-60), in granular form, produced by electrofusion and commonly used as an abrasive product. These particles, of maximum $8 \mathrm{~mm}$, are cheap and readily obtainable. A vinylester resin (Plastiform Epovia RF-1001) was used for the matrix; this showed better mechanical behaviour at high strain rates than other thermosetting polymers considered in this work, as we will show in Section 5.

The task of the ceramic particles is to erode the projectile and to distribute the load over a wide area of the metallic or laminate backing plate. So the content should be as high as the resin will admit without loss of the necessary cohesion. On the other hand, a low porosity material avoids stress concentration and prevents the premature fragmentation of the material that damages its impact behavior [2]. So the method of manufacture could give a material with a high volume fraction of ceramic and low porosity.

At present, the production of similar composite materials made up of ceramic powder and resin cement, of application in the dental industry [6,7], is by an expensive method of silanation of bioactive ceramic particles with high molecular weight PMMA resin. The composite we describe uses an alternative low cost manufacturing process.

The stages of the manufacturing process are summarized in Fig. 2: mixing, uniaxial compaction and unmolding. All the components (resin, catalyser, activator and particles) are mixed in their correct proportions to form a homogeneous cohesive material. We classified the particles by size and blended the resulting sets in different proportions to gauge the importance of grain size in the ballistic efficiency of the composite. The catalyst used, cumene hydroperoxide, starts the polymerisation process at room temperature and the activator, a cobalt octoate solution, accelerates the polymerization reactions. The uniaxial compaction is a decisive step towards reaching a high content of ceramic since it amasses the particles, evacuates the vinylester resin and reduces the porosity [8]. So by regulating the pressure of compaction, the tiles are formed of different ratios of ceramic/resin. The maximum pressure reached in the process was $6 \mathrm{MPa}$. After unmolding, the polymerized composite was cured for a period of two hours at $80{ }^{\circ} \mathrm{C}$.

The manufacturing process demands few operations - vacuum is not necessary - and allows good dimensional precision which facilitates molding. It also allows the production of tiles with a wide range of thicknesses, assuring strict control of the areal density. It is advisable however to manufacture tiles of thicknesses

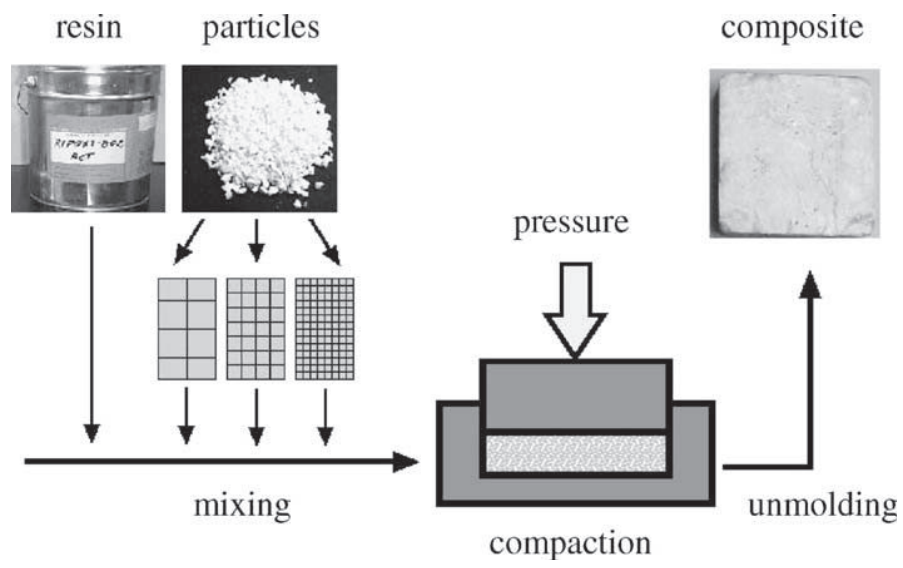

Fig. 2. Stages of the manufacturing process. 


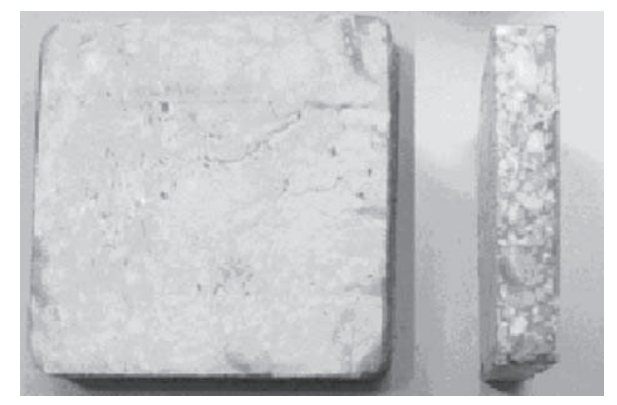

Fig. 3. Tile of vinylester resin and alumina particles. Front view (left) and cross-section (right).

Table 1

Approximate costs of materials commonly used for ballistic protection compared to that of the developed material

\begin{tabular}{ll}
\hline Material & $\begin{array}{l}\text { Approximate cost per kg } \\
\text { (normalized by the cost of } \\
\text { alumina particles) }\end{array}$ \\
\hline 95\% purity monolithic alumina & 28 \\
2017-T451 aluminum & 8 \\
Rolled homogeneous armour steel & 2.7 \\
Vinylester & 4 \\
$99.4 \%$ purity alumina particles & 1 \\
$80 \%$ alumina particles $+20 \%$ & 1.6 \\
vinylester (weight) & \\
\hline
\end{tabular}

greater than twice the largest particle size to avoid irregularities. This way, the method could give a material with a ceramic volumetric content of $50 \%(80 \%$ weight content) and less than $2 \%$ porosity (Fig. 3), prepared from low cost materials. A comparison of the costs of the materials commonly used for armor applications and those of the components of the new material is given in Table 1.

\section{Static compressive behavior of the composite}

Research on different ceramic materials for lightweight armor applications has shown the relation between static compressive strength and ballistic efficiency $[9,10]$, so we examined the static compressive behavior of the composite by testing specimens of $20 \times 20 \times 20$ $\mathrm{mm}^{3}$ with four different ceramic volumetric contents $V_{\mathrm{C}}$

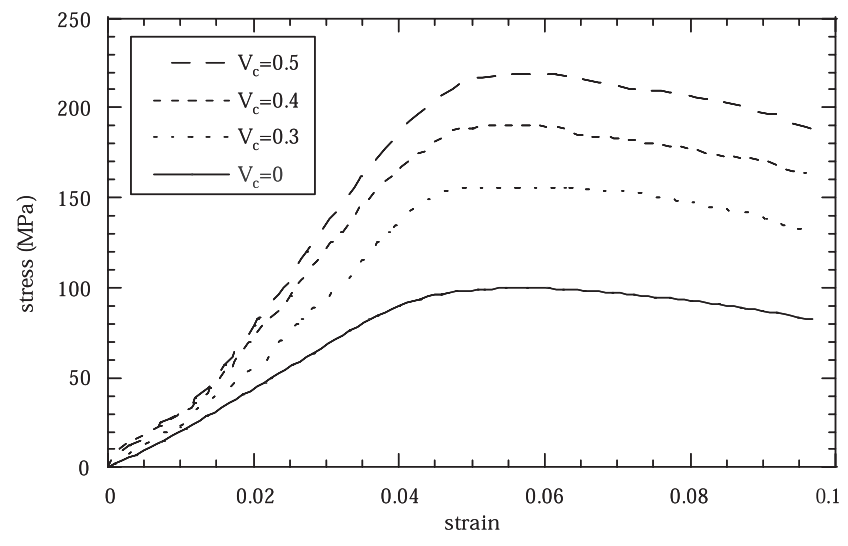

Fig. 4. Static stress-strain curves of the composite with different volumetric fractions of ceramic.

$(0 \%, 30 \%, 40 \%, 50 \%)$ in an Instron universal testing machine, fifteen tests for each material. Fig. 4. shows stress-strain curves representatives of the composite behavior. The material begins to show plastic strain starting from the convex zone of the curve. Extensive fragmentation of the resin matrix takes place beyond the maximum stress point. In the elastic range, the behavior is non linear up to $15 \%$ of the compressive yield stress and linear from this point. Table 2 shows the mean values of elastic modulus (in the linear range) and the compressive yield stress. The static properties depend on the ceramic content: a higher volumetric fraction of particles produces an increase of stiffness and raises the yield stress of the composite. This trend has been noted by other authors [11] for other ceramic/polymer materials (silica-filled epoxy resin). In view of our results above, composite tiles were made with the highest content of particles.

To calculate the properties of the composite from those of the components, two assumption could be adopted [12,13]: the equal-strain Voigt hypothesis and the uniform-stress Reuss hypothesis, that yield to the rule of mixtures and the inverse rule of mixtures, respectively. Eq. (1) (uniform-stress hypothesis) was used to find the mechanical properties obtained from the compression tests:

$P_{\mathrm{CM}}=\frac{1}{\frac{V_{\mathrm{C}}}{P_{\mathrm{C}}}+\frac{1-V_{\mathrm{C}}}{P_{\mathrm{R}}}}$

Table 2

Theoretical values and experimental mean values ( \pm standard deviation) of the elastic modulus $E_{\mathrm{CM}}$, and yield stress $Y_{\mathrm{CM}}$, of the composites with different volumetric fractions of ceramic

\begin{tabular}{llllc}
\hline$V_{\mathrm{C}}$ & $E_{\mathrm{CM}}[\mathrm{MPa}]$ & & $Y_{\mathrm{CM}}[\mathrm{MPa}]$ & \\
\cline { 2 - 3 } \cline { 5 - 5 } & Theoretical & Experimental & & Theoretical \\
\hline 0 & 2500 & $2500 \pm 46$ & 90 & $90 \pm 6$ \\
0.3 & 3558 & $3600 \pm 52$ & 126 & $140 \pm 8$ \\
0.4 & 4143 & $4300 \pm 62$ & 146 & $170 \pm 9$ \\
0.5 & 4957 & $5150 \pm 65$ & 172 & $190 \pm 12$ \\
\hline
\end{tabular}


where $P_{\mathrm{CM}}$ is a generic property of the composite, $P_{\mathrm{C}}$ and $P_{\mathrm{R}}$ the properties of the ceramic particles and of the resin. Adopting the mechanical properties of the ceramic particles (elastic modulus $=290 \mathrm{GPa}$; compressive strength $=2.1 \mathrm{GPa})$, this expression yields theoretical values of the elastic modulus and the yield stress close to the experimental values, as shown in Table 2. So the inverse rule of mixture seems adequate to determine the influence of the ceramic content in the improvement of the mechanical properties of the composite.

\section{Evaluation of the ballistic efficiency of the composite}

The geometry and the type of the backing plate in a ceramic/metal protection play a large part in determining the behavior on impact of the ceramic tile [14]. The method adopted to examine the behavior of a material without a backing plate is the depth of penetration (DOP) test [15-17] in which the material is backed by a metal block and impacted by a projectile. The residual penetration of the block, $d$ (Fig. 5b) is measured and compared to the reference penetration, $d_{\mathrm{REF}}$, into the metallic block without tile (Fig. 5a). Some authors [18] recommend additional tests (Fig. 5c) of ceramic/metal armors in the form in which the tile will be used. All these were included in our experimental analysis.

The projectile used was a LAPUA 7.62 AP with a tungsten carbide core of $5.9 \mathrm{~g}$ and length/diam. $=3.6$ (Fig. 6). The impact velocity was $940 \mathrm{~m} / \mathrm{s}$. A $100 \times 100 \times$ $100 \mathrm{~mm}^{3}$ block of 2017-T451 aluminum clamped at its rear face was used to perform the tests. The aluminum (a)

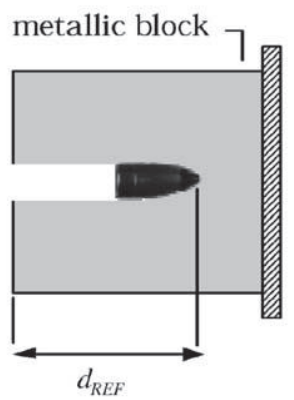

(b)
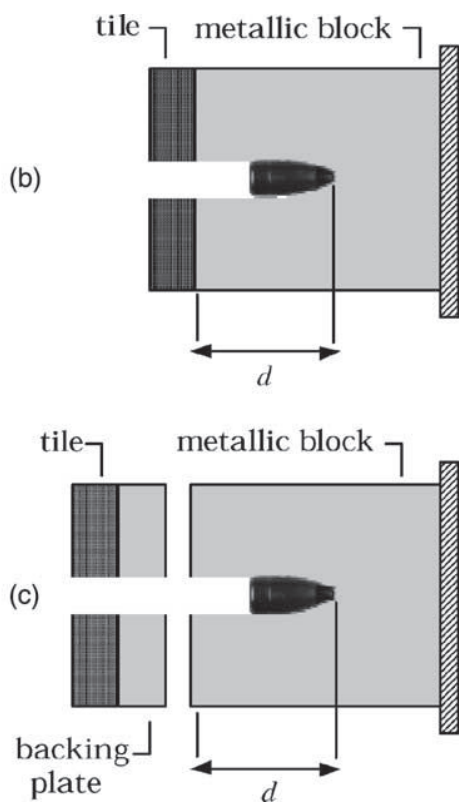

Fig. 5. (a) Reference penetration, (b) residual penetration with ceramic tile cover and (c) residual penetration with ceramic/metal armor cover.

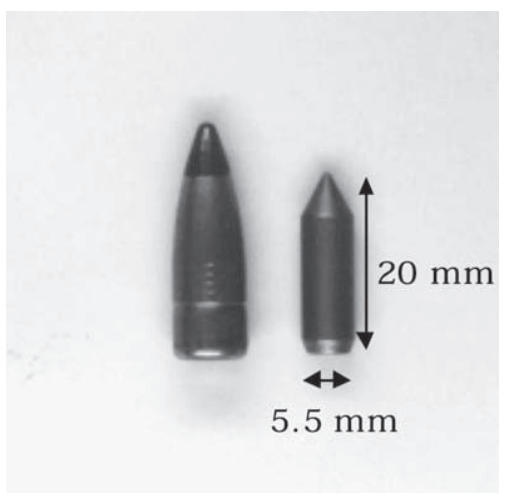

Fig. 6. LAPUA 7.62 AP projectile and its tungsten carbide core.

chosen for the backing plate was also 2017-T451 with a cross-section of $100 \times 100 \mathrm{~mm}^{2}$. Ceramic and composite tiles were of the same cross-section.

\subsection{DOP tests of the composite tile}

Composite tiles of three different thicknesses $(10,15$ and $20 \mathrm{~mm}$ ) and two different proportions of grain size intervals (Table 3 ) were tested, always with the same volumetric fraction of ceramic particles $\left(V_{\mathrm{C}}=0.5\right)$. To compare the efficiency of the composite with that of a ceramic commonly used in this application, 6 and 8.4 mm thick tiles of $95 \%$ purity alumina (Morgan Matroc AD 95 Sintox FA) were also tested. The penetration data were measured with an ultrasonic device. The reference penetration, $d_{\mathrm{REF}}$, in the uncovered aluminum block was $42 \mathrm{~mm}$.

Some parameters have been defined to determine the ballistic efficiency of a material $[16,17]$. One of them is the slope of the curves of non-dimensional residual penetration $d / d_{\text {REF }}$ versus areal density of the tile. Fig. 7 shows these curves for the experimental data obtained: the residual penetration decreases linearly with the tile areal density, which is characteristic of monolithic ceramic tiles $[14,15]$. The efficiency of the composite material is midway between that of armor aluminum and monolithic alumina. Grain size affects the efficiency of the composite: the larger the size the less the penetration into the block. The projectile has to produce a radial flow in the material of the tile in order to advance, and it is the smallest particles that offer least resistance to the penetration of the projectile.

Table 3

Proportions of grain size in manufactured tiles $(\bar{\delta}=$ grain mean size $)$

\begin{tabular}{cllll}
\hline & $1-3 \mathrm{~mm}$ & $3-6 \mathrm{~mm}$ & $5-8 \mathrm{~mm}$ & $\bar{\delta}(\mathrm{mm})$ \\
\hline $\begin{array}{c}\text { Large grain } \\
\text { composite }\end{array}$ & $20 \%$ & $30 \%$ & $50 \%$ & 4.5 \\
$\begin{array}{c}\text { Small grain } \\
\text { composite }\end{array}$ & $50 \%$ & $30 \%$ & $20 \%$ & 3.0 \\
\hline
\end{tabular}




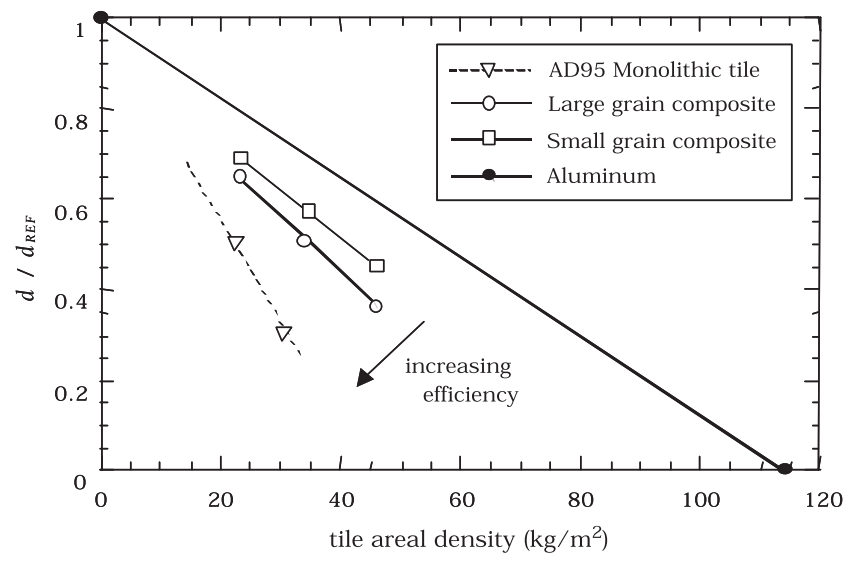

Fig. 7. Non-dimensional residual penetration versus areal density of the materials.

\subsection{DOP tests of compositelmetal armors}

To compare the efficiency of composite/metal armors with that of other materials commonly used in this application, tests were made on metallic plates (SAE 4130 steel and 2017-T451 aluminum) and on panels of monolithic alumina/aluminum (Morgan Matroc AD Sintox FA/2017-T451 Al). Both composite and monolithic ceramic tiles were bonded to the backing plate with Hysol EA 9361 epoxy. See Table 4 for the characteristics of these armors. The data of penetration (Fig. 8) demonstrate that for an equal areal density of the armor, the mixed protections of composite/aluminum were found to be more efficient than those of metallic materials. Here again the size of the ceramic particles is influential, the large grain providing greater efficiency on impact.

\section{Mechanical model for the composite material}

The design of armour panels is commonly made from the composite material empirically, relying on real im-

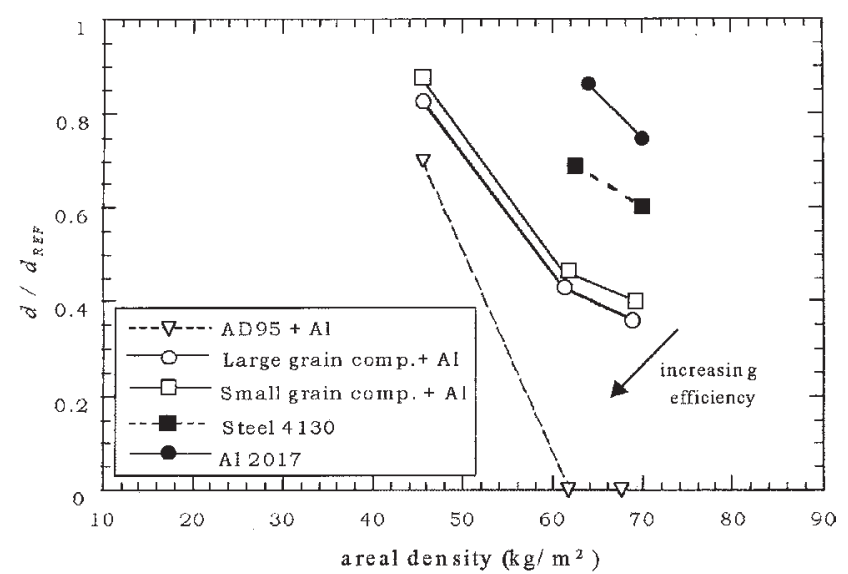

Fig. 8. Non-dimensional residual penetration versus areal density.

pact tests and using a given projectile and target in each test. It is a foolproof method but the results are valid only for the configuration tested and are not readily extrapolated; any variation of the impact velocity of the characteristics of the projectile or of the target invalidates the test data. It is also costly; testing in these conditions calls for sophisticated installations and equipment. It was the need to design stimulation tools that triggered the development of a constitutive model of the composite.

To model the behavior of the ceramic fraction of the composite material, we adopted the model of Cortés et al. [19], developed specifically for ceramic materials subjected to impact loading. It handles the diminution of the properties of the fragmented ceramic by including a damage parameter $\eta$ which affects the yield stress. This parameter quantifies the state of deterioration in a given volume, assigning $\eta=0$ to the intact material and $\eta=1$ to the part that is completely fragmented, associating the degree of fragmentation with the level of damage. So at a given instant it is assumed that in a specific volume, one fraction $\eta$ of the material is completely fragmented

Table 4

Compositions and areal densities of the tested armors

\begin{tabular}{|c|c|c|c|c|}
\hline Tile & Metal & Tile thickness (mm) & Metal thickness (mm) & Armour areal density $\left(\mathrm{kg} / \mathrm{m}^{2}\right)$ \\
\hline- & SAE 4130 Steel & - & 8 & 62 \\
\hline- & SAE 4130 Steel & - & 9 & 70 \\
\hline- & 2017-T451 Al & - & 23 & 63 \\
\hline- & 2017-T451 Al & - & 25 & 69 \\
\hline Alumina 95\% & 2017-T451 Al & 6 & 8 & 45 \\
\hline Alumina 95\% & 2017-T451 Al & 12 & 6 & 62 \\
\hline Alumina $95 \%$ & 2017-T451 Al & 8.4 & 13 & 68 \\
\hline Large grain composite & 2017-T451 Al & 10 & 8 & 45 \\
\hline Large grain composite & 2017-T451 Al & 19 & 6 & 61 \\
\hline Large grain composite & 2017-T451 Al & 14 & 13 & 69 \\
\hline Small grain composite & 2017-T451 Al & 12 & 8 & 40 \\
\hline Small grain composite & 2017-T451 Al & 19 & 6 & 61 \\
\hline Small grain composite & 2017-T451 Al & 14 & 13 & 69 \\
\hline
\end{tabular}


and a fraction $1-\eta$ is intact. The evolution of damage is determined with the equation

$\dot{\eta}= \begin{cases}\beta_{0}\left(\sigma-\sigma_{0}\right) & \text { for } \sigma>\sigma_{0} \\ 0 & \text { for } \sigma \leqslant \sigma_{0}\end{cases}$

where $\sigma$ is the hydrostatic stress (positive in tension), $\sigma_{0}$ the hydrostatic stress for the onset of fracture, and $\beta_{0}$ a parameter of the material. The yield stress, $Y_{\mathrm{C}}$, of the combination of ceramic, intact and fragmented, is calculated with both the fractions as in the equation

$Y_{\mathrm{C}}=(1-\eta) Y_{\mathrm{CI}}+\eta Y_{\mathrm{CF}}$

in which $Y_{\mathrm{CI}}$ is the yield stress of the intact material and $Y_{\mathrm{CF}}$ that of the fragmented portion. Accepting that the fragmented material presents a frictional behavior without cohesion, then

$Y_{\mathrm{CF}}=-\mu \sigma$ for $\sigma<0$

where $\mu$ is a coefficient of internal friction. The criterion assumed for the intact fraction is one of plasticity linearly dependent on the hydrostatic stress (of the type Drucker-Prager) in accordance with the behavior observed in ceramic materials

$Y_{\mathrm{CI}}=a-b \sigma$

The parameters $a$ and $b$ are defined by using typical values of the static tension and compression strength.

Compared to the monolithic ceramic material, the composite shows two important differences which are seen in the proposed model. The first is that the ceramic reinforcement already shows some initial fragmentation before impact since it is made up of fragments. This means that an initial damage value, $\eta_{0}$, must be defined for the material as a function of the grain size of the ceramic loading. The function proposed for this purpose associates the degree of damage with the size of the ceramic particle in such a way that the diminution of the size brings the damage towards unity, from the following expression:

$\eta=\frac{K}{\delta^{n}+K}$

in which $n$ and $K$ are constants. Once the damage value has been defined for each particle size, then the initial damage $\eta_{0}$ can be obtained by averaging (Fig. 9) the different grain sizes by means of the expression:

$\eta_{0}=\sum \eta_{i} P_{i}$

in which $P_{i}$ is the percentage per unit of each grain size, and $\eta_{i}$ its associated damage value. And then the behavior of the ceramic fraction is obtained from the model of Cortés et al. [19].

The other difference noted in the composite material is the existence of a polymeric matrix. We examined the dynamic compressive behavior of the matrix by testing specimens of $20 \mathrm{~mm}$ in diameter and $10 \mathrm{~mm}$ in length with different types of resin (Hysol EA 9361 epoxy,

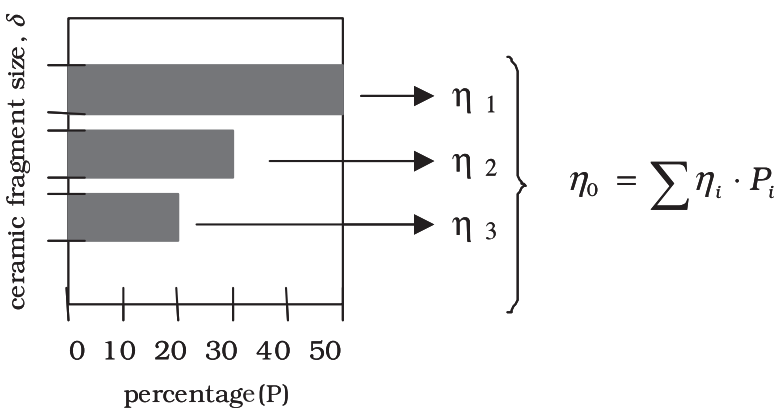

Fig. 9. Determination of the initial damage of the ceramic fraction from the sizes of the loading particles.

Estratil 1112 polyester and the vinylester resin we used) in a Split Hopkinson Pressure Bar, 15 tests for each material. Fig. 10 shows a marked viscoplastic behavior. So we adopted for the matrix a hardening equation dependent on the strain rate, as proposed by CowperSymonds and used by some authors [20,21] to determine the viscoplastic behavior of polymeric materials at high strain rates:

$Y_{\mathrm{R}}=\left(Y_{\mathrm{R} 0}+C_{1} \varepsilon_{\mathrm{R}}^{x}\right)\left(1+\left(C_{2} \dot{\varepsilon}_{\mathrm{R}}\right)^{z}\right)$

where $Y_{\mathrm{R}}$ is the yield stress of the resin, $Y_{\mathrm{R} 0}$ its static value, $\varepsilon_{\mathrm{R}}$ and $\dot{\varepsilon}_{\mathrm{R}}$ are respectively the plastic strain and plastic strain rate, and $C_{1}, C_{2}, z$, and $x$ are material constants. The vinylester resin showed better mechanical properties at high strain rate than the other resins (Fig. $10)$.

The properties of the composite are obtained from the mechanical properties of the two constituents. From the results of the static characterization of the material, a rule of homogenization was adopted, based on the hypothesis of constant stress, for the elastic properties as well as for the yield stress, and so Eq. (1) is applied to obtain a generic property, $P_{\mathrm{CM}}$.

\section{Validation of the mechanical model of the composite}

The model was validated by comparing the results of DOP tests for the composite material with those obtained by numerical simulation. The tool used for simulating the impact tests was the commercial finite difference code AUTODYN-2D [22], which solves the complete set of continuum mechanics equations, and considers stress wave propagation and plastic deformation of the solids, and is normally used for high strain rate dynamic problems. The properties of the materials used in the simulation were the following.

For the tungsten carbide core of the LAPUA 7.62 AP projectile we used the model of Cortés et al. [19] (Table 5 ). For the epoxy resin, used adhesive in mixed armours, we considered the Cowper-Symonds hardening equation (properties in Table 6). For the aluminum of the 

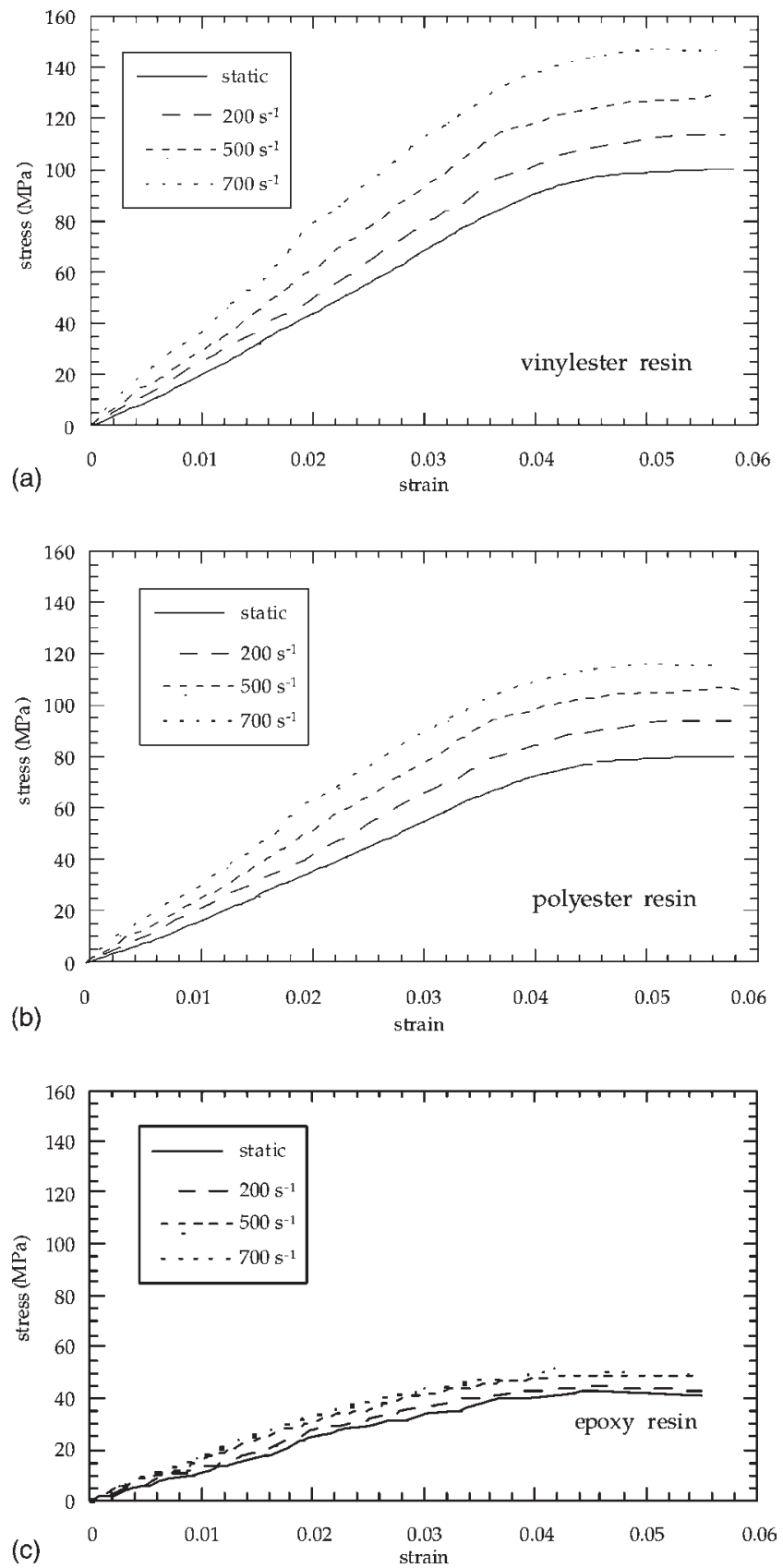

Fig. 10. Dynamic stress-strain curves at different strain rates for different types of resin: (a) vinylester resin, (b) polyester resin and (c) epoxy resin. backing plate and of the block used to measure penetration in the DOP tests, we used the Steinberg-Guinan hardening equation [23], which assumes that the shear modulus, $G_{\mathrm{M}}$, rises with the pressure, $p$, and diminishes with temperature, $T$, as expressed by

$G_{\mathrm{M}}=G_{\mathrm{M} 0}\left[1+\left(\frac{G_{\mathrm{p}}^{\prime}}{G_{\mathrm{M} 0}}\right) \frac{p}{\kappa^{1 / 2}}+\left(\frac{G_{T}^{\prime}}{G_{\mathrm{M} 0}}\right)(T-300)\right]$

in which $G_{\mathrm{M} 0}, G_{\mathrm{p}}^{\prime}$ and $G_{T}^{\prime}$ are material constants and $\kappa$ the ratio of the initial volume to the final volume. The yield stress $Y_{\mathrm{M}}$ is considered as dependent on the pressure, the temperature and the plastic strain $\varepsilon_{M}$

$$
\begin{aligned}
Y_{\mathrm{M}}=Y_{\mathrm{M} 0} & {\left[1+\left(\frac{Y_{\mathrm{p}}^{\prime}}{Y_{\mathrm{M} 0}}\right) \frac{p}{\kappa^{1 / 2}}+\left(\frac{G_{T}^{\prime}}{G_{\mathrm{M} 0}}\right)\right.} \\
& \left.\times(T-300)\left(1+\beta \varepsilon_{\mathrm{M}}\right)^{s}\right]
\end{aligned}
$$

where $Y_{\mathrm{M} 0}, Y_{\mathrm{p}}^{\prime}, \beta$ and $s$ are material constants. The equation above is subjected to a maximum value of the yield stress

$Y_{\mathrm{M} 0}\left(1+\beta \varepsilon_{\mathrm{M}}\right)^{s} \leqslant Y_{\max }$

The property values of the 2017-T451 aluminum alloy are detailed in Table 7. The mechanical properties of composite material with ceramic loading are given separately: the values of the alumina particles [21] and of the vinylester resin (from the Hopkinson Bar tests of dynamic compression) are shown in Tables 6 and 8.

Having chosen the constitutive equations and implemented the model of mechanical behavior of the composite with the user subroutine of the AUTODYN code we made the simulations considering axial symmetry. We used the configurations of the two types of fire tests: DOP with the composite tile cover (Fig. 5b) and DOP with the composite/metal cover (Fig. 5c). Fig. 11 illustrates the two-dimensional grid used in the simulation of the DOP test with composite tile cover. The position of the projectile on arrest at the end of the simulation allowed the determination of the residual penetration. Figs. 12 and 13 sketch the residual penetration into the block as calculated by numerical simulation, close to the experimental values. The model gives correctly the influence of particle size on the efficiency of the composite against impact.

\section{Conclusions}

A composite of polymeric matrix with low cost ceramic loading for protection against impact, manufactured as described, is notable for its simplicity and for the abundance of the materials used in its manufacture. The efficiency against impact afforded by tiles of the composite with a backing of aluminum is halfway 
Table 6

Properties of the polymers

\begin{tabular}{lllllll}
\hline & $Y_{\mathrm{R} 0}(\mathrm{MPa})$ & $C_{1}(\mathrm{MPa})$ & $C_{2}\left(\mathrm{~s}^{-1}\right)$ & $x$ & $z$ & $E(\mathrm{GPa})$ \\
\hline Vinylester & 21 & 1200 & $2.5 \times 10^{-4}$ & 1 & 5.6 & $2500-0.5 \dot{\varepsilon}+0.0025 \dot{\varepsilon}^{2}$ \\
Epoxy & 43 & 16 & $2.5 \times 10^{-4}$ & 1 & 5.3 & 2 \\
\hline
\end{tabular}

Table 7

Properties of the 2017-T451 aluminum alloy

\begin{tabular}{ll}
\hline$G_{\mathrm{M} 0}(\mathrm{MPa})$ & 27600 \\
$Y_{\mathrm{M} 0}(\mathrm{MPa})$ & 230 \\
$Y_{\max }(\mathrm{MPa})$ & 370 \\
$\beta$ & 125 \\
$s$ & 0.1 \\
$G_{\mathrm{p}}^{\prime}$ & 1.8 \\
$G_{T}^{\prime}(\mathrm{MPa})$ & -17 \\
$Y_{\mathrm{p}}^{\prime}$ & 0.018 \\
\hline
\end{tabular}

Table 8

Properties of the particles of alumina

\begin{tabular}{ll}
\hline Bulk modulus $(\mathrm{GPa})$ & 228 \\
Shear modulus $(\mathrm{GPa})$ & 150 \\
$\beta_{0}\left(\mathrm{MPa}^{-1} \mathrm{~s}^{-1}\right)$ & 2500 \\
$\sigma_{0}(\mathrm{MPa})$ & 100 \\
$\mu$ & 0.5 \\
$a(\mathrm{MPa})$ & 446.7 \\
$b$ & 2.7 \\
$n$ & 6 \\
$K$ & 1.2 \\
\hline
\end{tabular}
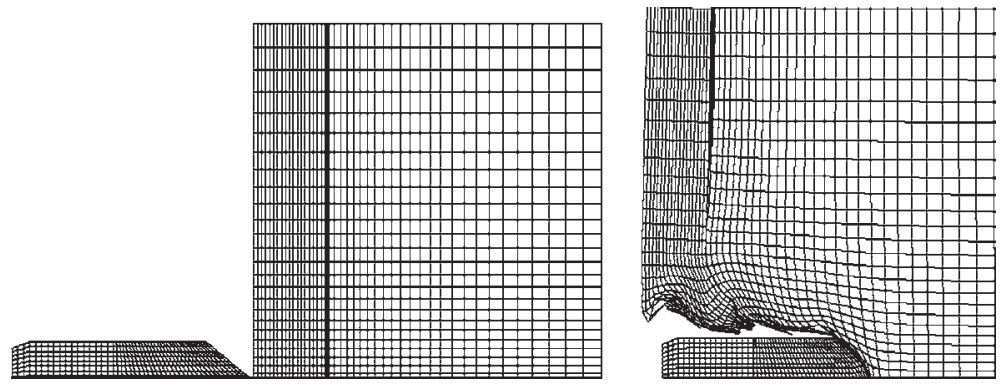

Fig. 11. Two-dimensional grids used in the simulation of the DOP test. Left: at the start of the simulation. Right: on arrest of the projectile.

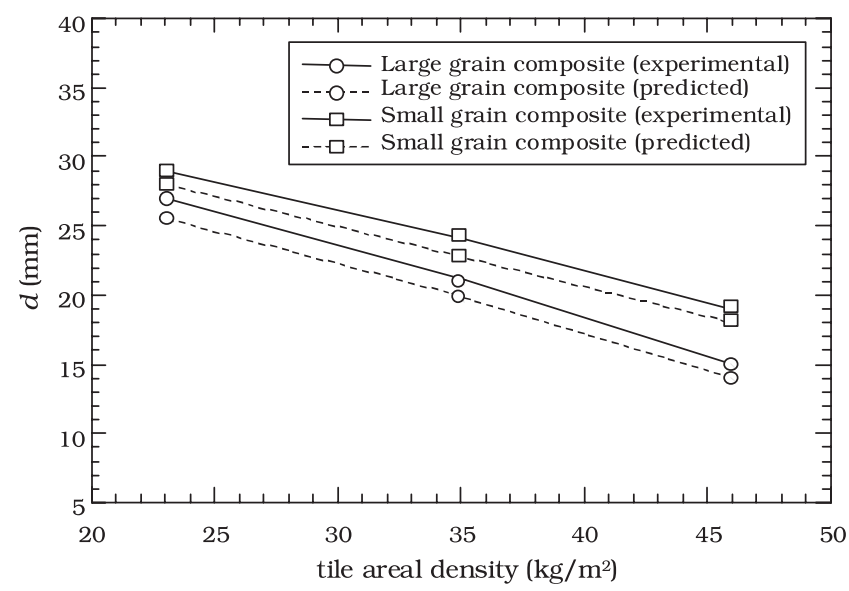

Fig. 12. Predicted and experimental values of the residual penetration versus areal density of the composite tile.

between that of the metals commonly used in these applications and the armors of monolithic ceramic/aluminum. These qualities justify the use of the composite for protections in which weight is not the primary concern and a cost saving is desirable.

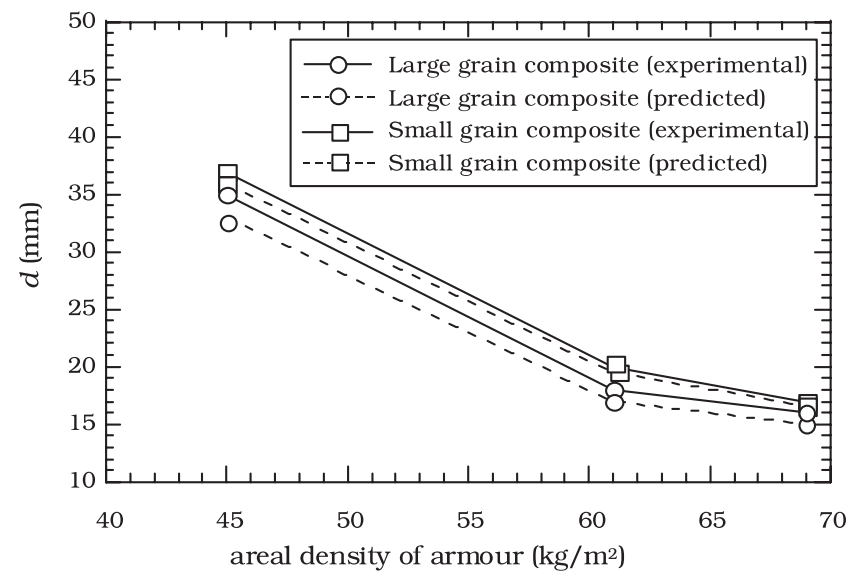

Fig. 13. Predicted and experimental values of the residual penetration versus areal density of the composite/metal armor.

The model of mechanical behavior developed to simulate the response of the composite to high velocity impact comes close to the experimental results. The model takes account of the proportion of loading/matrix, the grain size of the ceramic, and the contribution of each component to the properties of the composite. 


\section{Acknowledgement}

The authors are indebted to the Comunidad Autónoma de Madrid (Project 07N/0004/1998) for the financial support of this work.

\section{References}

[1] Cantwell WJ, Morton G. The impact resistance of composite materials. A review. Composites 1991;22(5):347-62.

[2] den Reijer PC. Impact on ceramic faced armours. PhD thesis. Delft University of Technology; 1991.

[3] Zaera R, Sánchez-Gálvez V. Analytical modelling of normal and oblique ballistic impact on ceramic/metal lightweight armours. Int J Impact Engng 1998;21:133-48.

[4] Roberson CJ. Ceramic materials and their use in lightweight armour systems. In: Proceedings Lightweight Armour System Symposium. Cranfield: Royal Military Collegue of Science; 1995.

[5] Matchen B. Applications of ceramics in armor products. Key Engng Mater 1996;122:333-42.

[6] Nakamura T, Kato H, Okada Y, Shinzato S, Kawanabe K, Tamura J, et al. Bone cement made of high molecular weight PMMA resin with bioactive ceramic filler showed higher bonebonding strength than that of bis-GMA resin and bioactive ceramic fillers. Bioceram, Key Engng Mater 2001;192(195):661-4.

[7] Mousa F, Kobayashi M, Shinzato S, Kamimura M, Masashi N, Yoshihara S, et al. Biological and mechanical properties of PMMA-based bioactive bone cements. Biomaterials 2000;21: 2137-46.

[8] Messing G, Markhoff C, McCoy L. Characterization of ceramic powder compactation. Ceram Bull 1982;61(8):857-60.

[9] Rozenberg Z, Yeshurun Y. The relation between ballistic efficiency and compressive strength of ceramic tiles. Int J Impact Engng 1988;7(3):357-62.

[10] Rozenberg Z, Bless SJ, Yeshurun Y, Okajina K. A new definition of ballistic efficiency based on the use of thick backing plates. In: Proceedings of Impact Conference, Bremen; 1987.
[11] Young RJ, Beaumont PWR. Failure of brittle polymers by slow crack growth. III. Effect of composition upon fracture of silica particle-filled epoxy resin composites. J Mater Sci 1977;12: 684-92.

[12] Ishai O, Cohen LJ. Elastic properties of filled and porous epoxy composites. Int J Mech Sci 1967;9:539-46.

[13] Smith JC. Experimental values for the static constants and particulate-filled glassy polymer. J Res NBS 1976;80A:45-9.

[14] Mayseless M, Goldsmith W, Virostek SP, Finnegan SA. Impact on ceramic targets. J Appl Mech 1987;54:373-8.

[15] Yaziv D, Rosenberg Z, Partom Y. Differential ballistic efficiency of applique armor. In: Proceedings on the 9th International Symposium on Ballistics, vol. 2, Shrivenham; 1986. p. 315-319.

[16] Hohler V, Stilp AJ, Weber K. Hypervelocity penetration of tungsten sinte-alloy rods into alumina. Int $\mathbf{J}$ Impact Engng 1995; 17:409-18.

[17] Anderson $\mathrm{Jr}$ CE, Morris BL. The ballistic performance of confined $\mathrm{Al}_{2} \mathrm{O}_{3}$ ceramic tiles. Int $\mathrm{J}$ Impact Engng 1992;12(2): 167-87.

[18] Mellgard I, Holmberg L, Gunnar L. An experimental method to compare the ballistic efficiencies of different ceramics against long rod projectiles. In: Proceedings on the 11th International Symposium on Ballistics, Jerusalem; 1989.

[19] Cortés R, Navarro C, Martínez-Casanova MA, Rodríguez J, Sánchez-Gálvez V. Numerical modelling of normal impact on ceramic composite armours. Int J Impact Engng 1992;12: 639-51.

[20] Grouch IG, Greaves LJ, Ruiz C, Harding J. Dynamic compression of toughened epoxy interlayers in adhesively bonded aluminium plates. J Phys IV 1994;C8:201-6.

[21] Zaera R, Sánchez-Sáez S, Pérez-Castellanos JL, Navarro C. Modelling of the adhesive layer in mixed ceramic/metal armours subjected to impact. Compos Part A: Appl Sci Manufact 2000;31(8):823-33

[22] AUTODYN-2D. Dynamic House, Horsam, West Sussex: Century Dynamics; 2001.

[23] Steinberg D, Cochran SG, Guinan MW. Constitutive model for metals applicable at high strain rates. J Appl Phys 1980;51(3): 1498-504 